\title{
Article
}

\section{Designing Peptide/Graphene Hybrid Hydrogels through Fine-Tuning of Molecular Interactions}

Wychowaniec, Jacek K., Iliut, Maria, Zhou, Mi, Moffat, Jonathan, Elsawy, Mohamed, Pinheiro, Wagner A., Hoyland, Judith A., Miller, Aline F., Vijayaraghavan, Aravind and Saiani, Alberto

Available at https://clok.uclan.ac.uk/23266/

Wychowaniec, Jacek K., Iliut, Maria, Zhou, Mi, Moffat, Jonathan, Elsawy, Mohamed orcid iconORCID: 0000-0003-3964-2150, Pinheiro, Wagner A., Hoyland, Judith A., Miller, Aline F., Vijayaraghavan, Aravind et al (2018) Designing Peptide/Graphene Hybrid Hydrogels through Fine-Tuning of Molecular Interactions. Biomacromolecules, 19 (7). pp. 2731-2741. ISSN 15257797

It is advisable to refer to the publisher's version if you intend to cite from the work. http://dx.doi.org/10.1021/acs.biomac.8b00333

For more information about UCLan's research in this area go to http://www.uclan.ac.uk/researchgroups/ and search for < name of research Group>.

For information about Research generally at UCLan please go to http://www.uclan.ac.uk/research/

All outputs in CLoK are protected by Intellectual Property Rights law, including Copyright law. Copyright, IPR and Moral Rights for the works on this site are retained by the individual authors and/or other copyright owners. Terms and conditions for use of this material are defined in the policies page.

\section{CLoK}

Central Lancashire online Knowledge www.clok.uclan.ac.uk

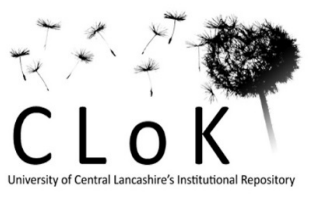




\title{
Designing Peptide/Graphene Hybrid Hydrogels through Fine-Tuning of Molecular Interactions
}

\author{
Jacek K. Wychowaniec, ${ }^{\dagger,+}$ (1) Maria Iliut, ${ }^{\dagger, \S}$ Mi Zhou, ${ }^{\|}$Jonathan Moffat, ${ }^{\perp}$ Mohamed A. Elsawy, ${ }^{\dagger,+, \$}$ \\ Wagner A. Pinheiro, ${ }_{\dagger}^{\dagger, \#}$ Judith A. Hoyland, ${ }^{\|, \nabla}$ Aline F. Miller, ${ }^{\ddagger, O}$ Aravind Vijayaraghavan, ${ }^{\dagger, \S_{0}}$ \\ and Alberto Saiani* ${ }^{* \dagger, \ddagger(0)}$
}

\begin{abstract}
${ }^{\dagger}$ School of Materials, The University of Manchester, Oxford Road, M13 9PL, Manchester, United Kingdom
${ }^{*}$ Manchester Institute of Biotechnology, The University of Manchester, Oxford Road, M13 9PL, Manchester, United Kingdom

${ }^{\S}$ National Graphene Institute, The University of Manchester, Booth Street East, M13 9PL, Manchester, United Kingdom

"Division of Cell Matrix Biology and Regenerative Medicine, Faculty of Biology, Medicine and Health, The University of Manchester, M13 9PL, Manchester, United Kingdom

${ }^{\perp}$ UK Asylum Research, An Oxford Instruments Company, Halifax Road, HP12 3SE, High Wycombe, United Kingdom

"Military Institute of Engineering, Praça Gen Tibúrcio 80, Urca, Rio de Janeiro, Rio de Janeiro 22290-270, Brazil

${ }^{\nabla}$ NIHR Manchester Musculoskeletal Biomedical Research Centre, Manchester Academic Health Science Centre, Central Manchester NHS Foundation Trust, Manchester M23 9LT, United Kingdom

OSchool of Chemical Engineering and Analytical Sciences, The University of Manchester, M13 9PL, Manchester, United Kingdom
\end{abstract}

\section{Supporting Information}

ABSTRACT: A recent strategy that has emerged for the design of increasingly functional hydrogels is the incorporation of nanofillers in order to exploit their specific properties to either modify the performance of the hydrogel or add functionality. The emergence of carbon nanomaterials in particular has provided great opportunity for the use of graphene derivatives (GDs) in biomedical applications. The key challenge when designing hybrid materials is the understanding of the molecular interactions between the matrix (peptide nanofibers) and the nanofiller (here GDs) and
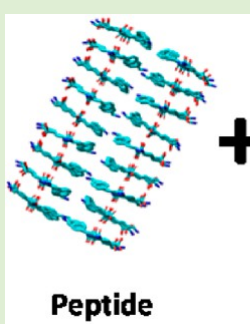

nanofibres

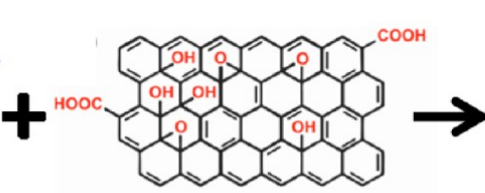

Graphene derivatives

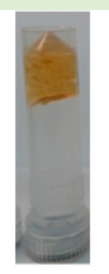

Hybrid hydrogels how these affect the final properties of the bulk material. For the purpose of this work, three gelling $\beta$-sheet-forming, selfassembling peptides with varying physiochemical properties and five GDs with varying surface chemistries were chosen to formulate novel hybrid hydrogels. First the peptide hydrogels and the GDs were characterized; subsequently, the molecular interaction between peptides nanofibers and GDs were probed before formulating and mechanically characterizing the hybrid hydrogels. We show how the interplay between electrostatic interactions, which can be attractive or repulsive, and hydrophobic (and $\pi-\pi$ in the case of peptide containing phenylalanine) interactions, which are always attractive, play a key role on the final properties of the hybrid hydrogels. The shear modulus of the hydrid hydrogels is shown to be related to the strength of fiber adhesion to the flakes, the overall hydrophobicity of the peptides, as well as the type of fibrillar network formed. Finally, the cytotoxicity of the hybrid hydrogel formed at $\mathrm{pH} 6$ was also investigated by encapsulating and culturing human mesemchymal stem cells (hMSC) over 14 days. This work clearly shows how interactions between peptides and GDs can be used to tailor the mechanical properties of the resulting hydrogels, allowing the incorporation of GD nanofillers in a controlled way and opening the possibility to exploit their intrinsic properties to design novel hybrid peptide hydrogels for biomedical applications.

\section{INTRODUCTION}

Progress in the cell culture and tissue engineering fields requires the design of novel functional biomaterials, in particular three-dimensional (3D) scaffolds. ${ }^{1-4}$ Hydrogels, which are highly hydrated materials, have come to the forefront in the design of such scaffolds, which need to be biocompatible, mechanically tunable, and offer opportunity for biofunctionalization. A variety of natural and synthetic molecular building blocks can be found in the literature that allows the design of such hydrogels. One such block, which has attracted significant interest in the past decade, is $\beta$-sheet forming peptides. In particular, the design devised by Zhang and co-workers, which is based on short peptides (typically 4 to 20 amino acids) with alternating hydrophilic and hydrophobic residues, has proven to hold significant potential for the formulation of biocompatible hydrogels for use in a range of applications from drug delivery

Received: February 25, 2018

Revised: April 7, 2018

Published: April 19, 2018 
to tissue engineering. ${ }^{5}$ Indeed these hydrogels have been shown to be able to sustain the $3 \mathrm{D}$ culture of a variety of cells ${ }^{6-12}$ and to be suitable for use in vivo. ${ }^{13-16}$

A recent strategy that has emerged for the design of increasingly functional hydrogels is the incorporation of nanofiller in order to exploit their specific properties to either modify the performance of the hydrogel or add functionality. ${ }^{17-20}$ The emergence of carbon nanomaterials in particular has provided great opportunities for the use of graphene derivatives (GDs) in biomedical applications. ${ }^{21-23}$ Recently, incorporation of graphene-based nanofillers in hydrogels has been used to tailor mechanical strength and conductivity and add binding sites for biofunctionalization to regulate cell behavior, including proliferation, differentiation and protein synthesis to promote specific tissue regeneration. ${ }^{24-27}$ As underlined by a number of authors, the key challenge when designing hybrid materials is the understanding of the molecular interactions between the matrix and the nanofiller and how these affect the final properties of the bulk material. $^{28-31}$ In the case of peptide/GDs hybrid hydrogels, these include the molecular interaction between peptide fibers and GDs and how these interactions can be manipulated by design, through modification of the peptide sequence and/or the GDs surface chemistry, to tailor the final properties and functionality of the hydrogel.

For the purpose of this work, three peptides with varying physiochemical properties and five GDs with varying surface chemistries have been used to formulate novel hybrid hydrogels. First, the peptide hydrogels and the GDs were characterized individually; subsequently, the molecular interaction between peptides fibers and GDs were probed, before formulating and mechanically characterizing the hybrid hydrogels. Finally, the potential biocompatibility of the hybrid hydrogel formed at $\mathrm{pH} 6$ was investigated by culturing human mesenchymal stem cells (hMSC) in 3D. This work provides new insight into how molecular interactions between peptide fibers and GDs affect the bulk properties of this family of peptide hydrogels, providing new design opportunities for the formulation of functional hybrid hydrogels with tailored properties.

\section{MATERIALS AND METHODS}

Peptides. All peptides were purchased from Biomatik Corporation (Wilmington, DE, Canada) with a purity $>90 \%$ [confirmed in-house by mass spectrometry (MS) and reverse phase high performance liquid chromatography (HPLC)]. Peptide ClogP values were estimated using ChemDraw Professional 16.0 software. Peptides residues were charged accordingly to the chosen $\mathrm{pH}$ values. All solvents and reagents were purchased from Sigma-Aldrich and used as received.

Graphene Oxide (GO) and Reduced GO (rGO) Preparation. GO used in this study was prepared by a modified Hummer's method. $^{32}$ Briefly, graphite (10 g, 80 mesh, 94\% carbon) was first treated with $\mathrm{NaNO}_{3}(9 \mathrm{~g})$ and concentrated $\mathrm{H}_{2} \mathrm{SO}_{4}(338 \mathrm{~mL})$ at room temperature (RT) for $3 \mathrm{~h}$ to obtain intercalated graphite. The mixture was then cooled in an ice bath, and $45 \mathrm{~g}$ of $\mathrm{KMnO}_{4}$ was gradually added. After addition of the oxidizing agent, the reaction mixture was stirred at room temperature for 1 week to complete the oxidation. The oxidized graphitic slurry was then diluted with a solution of $5 \% \mathrm{H}_{2} \mathrm{SO}_{4}$, followed by slow addition of $5 \mathrm{~g}$ of $\mathrm{H}_{2} \mathrm{O}_{2}$ as solution. The resulting GO was purified by repeated centrifugation and redispersion in deionized (DI) water until the $\mathrm{pH}$ of the supernatant was neutral. The size distribution of GO flakes was characterized using scanning electron microscopy (Zeiss Ultra FEG SEM). Samples were prepared by spin coating $\mathrm{GO}$ flakes onto a $\mathrm{Si} / \mathrm{SiO}_{2}$ wafer to get monolayer coverage with minimal flake overlap. For each dispersion, the size of
200 flakes from multiple SEM images was measured manually using ImageJ software. In order to avoid shape anisotropies to skew the distribution results, measurements were performed in the horizontal direction through the center of the flake, assuming that the drying process did not introduce any orientation anisotropy. rGO was prepared by reducing the GO in solution at $80^{\circ} \mathrm{C}$ for $72 \mathrm{~h}$ in the presence of ascorbic acid as reducing agent (1:7 GO to ascorbic acid mass ratio). Ammonia was then added to produce a basic dispersion $(\mathrm{pH} \sim 10)$. The resulting rGO was purified by repeated centrifugation and redispersion in DI water.

GO and rGO Polymer-Coated Flakes Preparation. Polymer coated GO flakes were prepared by dissolving dry polymer (polydiallyldimethylammonium chloride - PDADMAC or polyvinylpyrrolidone - PVP) pellets into a $2 \mathrm{mg} \mathrm{mL}^{-1} \mathrm{GO}$ water dispersion (1:10 GO to polymer solids mass ratio). The mixture was homogenized for 5 min using a high-shear mixer to ensure a uniform $\mathrm{GO} /$ polymer "stock" dispersion. The mixture was then washed 3 times with DI water by repeated centrifugation and redispersion to remove any excess of nonadsorbed polymer. In order to prepare the polymer coated rGO flakes, the GO/polymer "stock" dispersion obtained above was reduced at $80{ }^{\circ} \mathrm{C}$ for $72 \mathrm{~h}$ in the presence of ascorbic acid as reducing agent (1:7 GO to ascorbic acid mass ratio). Ammonia was then added to produce a basic dispersion $(\mathrm{pH} \sim 10)$. The mixture was then washed 3 times as described above to remove any nonadsorbed polymer.

Dispersions/Hydrogels Preparation. The desired amount of peptides were dissolved in $350 \mu \mathrm{L}$ of double distilled water $\left(\mathrm{ddH}_{2} \mathrm{O}\right)$. When dispersions and hybrid hydrogels were prepared, the desired graphene derivatives (except for rGO see below) were added to the peptide solution at this stage. Dispersions/hydrogels were then prepared by adjusting the $\mathrm{pH}$ using a $0.1 \mathrm{M} \mathrm{NaOH}$ solution to the desired value. The total sample volume was then adjusted by further addition of $\mathrm{ddH}_{2} \mathrm{O}$ to achieve the desired concentration. To obtain peptide + rGO dispersions and hybrid hydrogels, GO was added to the peptide solution and reduced in situ by adding ascorbic acid ${ }^{33}$ using the same protocol as for the preparation of $\mathrm{rGO}\left(1 \mathrm{~h}\right.$ at $\left.80^{\circ} \mathrm{C}\right)$. MS and RP-HPLC were used to confirm that the peptides were not degraded by the reduction process. The hydrogels were then prepared as described above by adjusting the $\mathrm{pH}$ of the sample to the desired value.

Zeta Potential $(\zeta)$ Measurements. The charge of the GDs dispersions was measured at $0.01 \mathrm{mg} \mathrm{mL}^{-1}, \mathrm{RT}$ and $\mathrm{pH} 3.5$ and 6 using a Malvern Zetasizer ESA9800 instrument. The measurements were repeated 3 times to ensure reproducibility and could only be performed on the water-dispersible GDs. ${ }^{34}$

Fourier Transform Infrared (FTIR) Spectroscopy. Measurements were performed on a Bruker Vertex 80 FTIR spectrometer equipped with a diamond ATR accessory. The beam path was purged with dry $\mathrm{CO}_{2}$-scrubbed air. Spectra were obtained using resolution of 4 $\mathrm{cm}^{-1}$ and were an average of 128 scans to ensure a good signal-tonoise ratio. A dd $\mathrm{H}_{2} \mathrm{O}$ background was subtracted from all spectra. Measurements were done in triplicate to ensure reproducibility. The FTIR spectra were normalized by setting the $\beta$-sheet peak (1625 $\mathrm{cm}^{-1}$ ) at $100 \%$ using GraphPad 7.0.

Atomic Force Microscopy (AFM). The AFM imaging of the GDs was performed using a Dimension FastScan microscope (Bruker, USA). Samples were scanned in air, at room temperature, using tapping mode with FASTSCAN-A probes (Bruker, USA). The images were acquired at $512 \times 512$ pixels resolution over $10 \times 10 \mu \mathrm{m}$ area at a scan rate of $3 \mathrm{~Hz}$. For the substrate preparations, GO, GO/ PDADMAC, rGO/PDADMAC, rGO/PVP were diluted from the original dispersions to $0.6 \mathrm{mg} \mathrm{mL} \mathrm{m}^{-1}$ and deposited by spin coating them on a $\mathrm{Si} / \mathrm{SiO}_{2}$ substrate. The reference $\mathrm{rGO}$ was prepared using a dilute GO dispersion $\left(0.1 \mathrm{mg} \mathrm{mL}^{-1}\right)$ as described above and then spin coated. These AFM images were processed using WSxM 5.0 Develop 8.1 software. ${ }^{35}$ AFM imaging of the peptide solution and peptide/GDs dispersions was carried out using a Cypher S (Oxford Instruments Asylum Research, USA). Measurements were acquired in AC mode with AC240TS probes (Olympus Probes, Japan). Images were acquired at a resolution of $512 \times 512$ pixels over scan sizes ranging 
from 20 to $1.5 \mu \mathrm{m}$ at a scan rate of $1 \mathrm{~Hz}$. Samples were prepared by drop-casting a $10 \mu \mathrm{L}$ droplet of the solution/dispersion on freshly cleaved mica for $2 \mathrm{~min}$, followed by rinsing with water and drying with compressed air. For samples that would not adhere to mica, mica was coated with poly-L-lysine (PLL) by incubating it with a $0.01 \%$ PLL solution for $2 \mathrm{~min}$, followed by rinsing with water and drying with compressed air. Areas of the sample were selected that allowed covisualization of peptide fibers and the GD flakes. For some samples, spin coating was used instead of drop-casting in order to obtain images showing fibers and flakes.

Oscillatory Rheology. Oscillatory rheology was performed on a Discovery Hybrid 2 (DHR-2) instrument (TA Instruments). Parallel plate geometry with a $250 \mu \mathrm{m}$ gap was used. All samples were equilibrated to $25{ }^{\circ} \mathrm{C}$ prior to measurements. About $200 \mu \mathrm{L}$ of sample was placed on the bottom plate using a spatula, and subsequently the top rheometer plate was lowered slowly to minimize hydrogel disruption. Frequency scans were performed from 0.1 to $15 \mathrm{~Hz}$ at $0.2 \%$ strain within the linear viscoelastic regime of the samples. All measurements were repeated at least three times to ensure reproducibility. Shear moduli values are represented as mean $\pm S E$, measured at an angular frequency of $1 \mathrm{rad} \mathrm{s}^{-1}$.

Small Angle X-ray Scattering (SAXS). SAXS experiments were performed on beamline I22 at the Diamond Light Source (DLS) facility in Didcot, UK. The energy of the beam was $12.4 \mathrm{keV}$ corresponding to the X-ray wavelength of $0.1 \mathrm{~nm}$. Quartz capillaries (1.5 mm outer diameter, $0.01 \mathrm{~mm}$ wall thickness) were purchased from Capillary Tube Supplies, Ltd. Peptide solutions/hydrogels were prepared as described above at 4.5 and $8.9 \mathrm{mM}$ and introduced in the capillaries using a syringe. Acquisition time was $1 \mathrm{~s}$, and the area pixel array detector used to collect the SAXS patterns was a Pilatus P3-2 M (Dectris). The distance between sample and detector was fixed to 3.47 $\mathrm{m}$, resulting in a momentum transfer vector range of $0.059<q\left(\mathrm{~nm}^{-1}\right)$ $<3.067$ with $q=(4 \pi / \lambda) \sin (\theta / 2)$, where $\theta$ is the scattering angle and $\lambda$ is the wavelength of incident beam. Calibration of the momentum transfer was performed using silver behenate powder. $\mathrm{ddH}_{2} \mathrm{O}$ was used as background and subtracted from all the SAXS patterns. Data were reduced using the DawnDiamond software suite. The $2 \mathrm{D}$ scattering patterns were integrated using azimuthal integration to obtain 1D scattering patterns. Under these conditions, the coherent absolute intensity scattered by the samples can be written as ${ }^{36-40}$

$$
I_{\mathrm{A}}(q)=\frac{1}{K}\left[I_{\mathrm{N}}(q)-\left(1-C_{\mathrm{p}}\right) I_{\mathrm{S}}(q)-I_{\mathrm{b}}\right]
$$

where $I_{\mathrm{N}}(q)$ is the normalized intensity scattered by the sample, $I_{S}(q)$ is the normalized intensity scattered by the water, $C_{\mathrm{p}}$ is the peptide concentration in $\mathrm{g} \mathrm{cm}^{-3}, I_{\mathrm{b}}$ is the background scattering mainly due to the incoherent scattering of the peptides, and $K$ is the contrast factor. The background scattering, $I_{\mathrm{b}}$, was estimated using the Porod law, which gives the scattered intensity of a two-phase system at high $q$ values: $:^{36-40}$

$$
I(q)=\frac{K_{\mathrm{p}}}{q^{4}}+I_{\mathrm{b}}
$$

where $K_{\mathrm{p}}$ is the Porod constant. $I_{\mathrm{b}}$ was estimated by fitting the last 10 data points of the scattering curves using a Porod representation $\left(q^{4} I(q)\right.$ vs $\left.q^{4}\right)$.

Cell Culture and Cytotoxicity Measurements. Human mesenchymal stem cells (hMSCs) were grown in $\alpha$-MEM medium supplemented with $10 \%(\mathrm{v} / \mathrm{v})$ fetal bovine serum (FBS), $L$-ascorbic acid-2 phosphate $(10 \mu \mathrm{M}), 1 \times$ Glutamax (Life Invitrogen, UK), and an antibiotic mixture of penicillin $\left(100\right.$ units $\left.\mathrm{mL}^{-1}\right)$, streptomycin $(100$ $\left.\mu \mathrm{g} \mathrm{mL}{ }^{-1}\right)$ and amphotericin $\left(0.25 \mu \mathrm{g} \mathrm{mL}^{-1}\right)$. Cells subcultured at $<80 \%$ confluency and $<$ passage 4 were used for the cytotoxicity assessments experiments. Hydrogels subjected to the cytotoxicity test (FE, FE + GO, and FE + rGO) were prepared as described above at $\mathrm{pH} 6$ and $26.8 \mathrm{mM} / 0.5 \mathrm{mg} \mathrm{mL} \mathrm{m}^{-1}$ peptide/GD concentrations. Hydrogels were prewarmed to $37{ }^{\circ} \mathrm{C}$, and then the cells were gently mixed in using the tip of a pipet to obtain a final homogeneous cell suspension of $1.5 \times 10^{6}$ cells $\mathrm{mL}^{-1}$ of hydrogel. The hydrogel were then plated into cell culture insert and media added around and on the top of the hydrogels. Culture media was then replaced 1 time during the initial hour, and then every other day up to 14 days. Cell viability measurements were performed at days 1,7 , and 14 . The cellcontaining hydrogels were incubated with a Live/Dead solution containing calcein AM and ethidium homodimer-1 (Invitrogen, Thermo-Fisher Scientific, UK), and then imaged using an Olympus BX51 fluorescence microscope (emission wavelengths: 515/635 nm, excitation wavelength: $495 \mathrm{~nm}$ ).

\section{RESULTS AND DISCUSSION}

We have recently investigated the self-assembly and gelation properties of a family of octa-peptide based on Zhang's design. It has been shown that these peptides form $\beta$-sheet rich fibers with the hydrophobic residues buried in the core, while the hydrophilic residues are located on the surface of the fibers (Figure 1C). ${ }^{41-43}$ As a result, we have shown that the

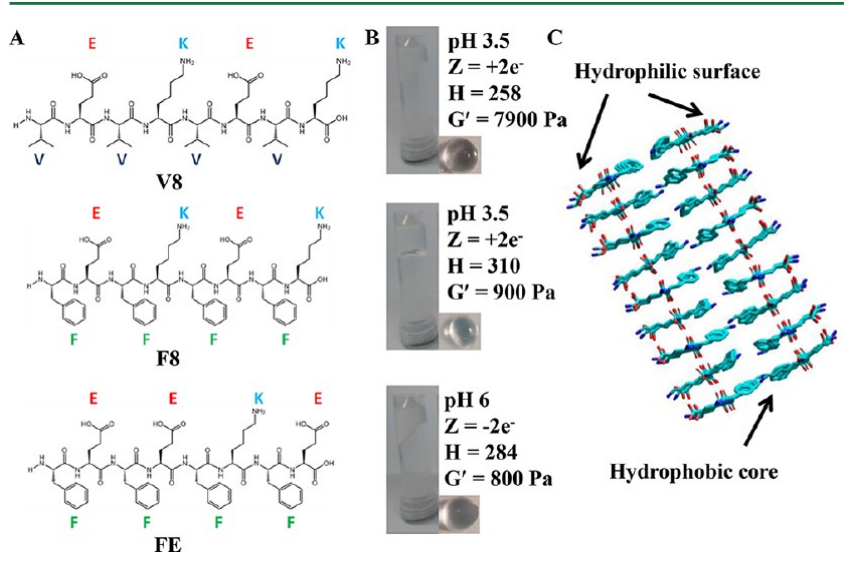

Figure 1. (A) Chemical structures of the three $\beta$-sheet forming peptides used in this study (V: valine; F: phenylalanine; K: lysine; E: glutamic acid). (B) Photograph of hydrogels obtained for the three peptides, $\mathrm{pH}$ at which the hydrogel was prepared, theoretical charge $(\mathrm{Z})$ and hydrophobicity $(\mathrm{C} \log \mathrm{P})$, and measured storage shear modulus $\left(G^{\prime}\right)$. (C) Schematic representation of the $\beta$-sheet fibers formed by these peptides showing the hydrophobic core and the hydrophilic surface.

hydrophobic residues control the self-assembly into $\beta$-sheet fibers as well as the fibers intrinsic properties such as persistence length, ${ }^{44}$ while the hydrophilic residues control fiber solubility, fiber-fiber interactions and network formation. ${ }^{42}$ In order to form stable and transparent hydrogels, and avoid excessive aggregation and precipitation of the fibers due to their intrinsic hydrophobicity, the peptides need to carry a charge, positive or negative, with a modulus $>1 .^{45,46}$

Three octa-peptides with varying hydrophilicities and charges were chosen for this study. VEVKVEVK (V8) and FEFKFEFK (F8) (V: valine; E: glutamic acid; K: lysine; F: phenylalanine; Figure 1) were selected as they differ in hydrophobicity, V being less hydrophobic than $F$. In addition, $F$ side group contains an aromatic ring able to interact through $\pi-\pi$ stacking with the surface of GDs. Indeed Nilsson et al. showed that the side group from the residue in the first position in this type of sequences can interact with the outer environment. ${ }^{47}$ Based on the peptide theoretical charge profiles (Figure ESI 1), hydrogels for these two peptides were formulated at $\mathrm{pH} 3.5, \mathrm{pH}$ at which they will carry a theoretically charge of $+2 \mathrm{e}^{-}$. A third peptide was also selected, FEFEFKFE (FE), as this peptide will have similar molecular properties to F8 but will be more hydrophilic and carry a theoretical charge of $-2 \mathrm{e}^{-}$at $\mathrm{pH} 6$ (Figure 1). The 
$\mathrm{pH}$ at which the hydrogels were formulated was kept constant throughout this study to keep the peptide charge constant. All three peptides form stable and transparent hydrogels at $\mathrm{pH} 3.5$ (V8 and F8) and $\mathrm{pH} 6(\mathrm{FE})$, respectively (Figure 1B). The adoption of $\beta$-sheet conformations by these three peptides was confirmed by FTIR. As can be seen from Figure 2A, all three

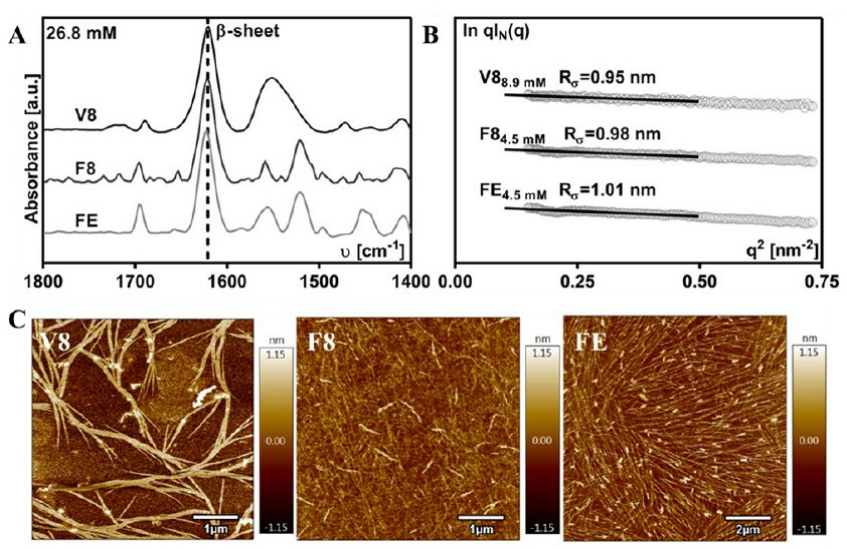

Figure 2. (A) Normalized FTIR absorption spectra obtained for the three peptide hydrogels. (B) SAXS pattern obtained at low $\mathrm{q}$ presented in a $\ln \left[q l_{n}(q)\right]$ vs $q^{2}$ representation $\left(R_{\sigma}\right.$ : cross-section radius of gyration estimated from the slope of the SAXS patterns). (C) AFM images of the self-assembled peptide fibers (samples concentration 0.5 $\mathrm{mM})$.

spectra present in the amide I region the typical strong $\beta$-sheet bands at $1625 \mathrm{~cm}^{-1}$ with the associated smaller band at 1695 $\mathrm{cm}^{-1}$. The formation of fibers was confirmed by SAXS. Experiments were performed at low concentrations to ensure dilute state conditions so that the scattering observed is dominated by the form factor of the diluted scattering entities. Scattering patterns with a $q^{-1}$ behavior at low $q$ were obtained typical of the scattering of long thin rod-like structures, in other words, fibers (Figure ESI 2). It has been previously shown that for such objects, for $q R_{\sigma}<1$ ( $R_{\sigma}$ : cross-section radius of gyration) the scattering intensity $I(q)$ can be written as ${ }^{36,40}$

$$
\ln q I(q) \propto-\frac{R_{\sigma}^{2}}{2} q^{2}
$$

As a result, in a $\ln \left[q l_{n}(q)\right]$ vs $\mathrm{q}^{2}$ representation, a linear behavior is obtained at low $q$ from the slope of which $R_{\sigma}$ can be estimated (Figure 2B). Assuming that the fibers can be modeled by a plain infinitely long cylinder, $R_{\sigma}$ is related to the diameter of the fiber, $d$, through $R_{\sigma}=\sqrt{\frac{d^{2}}{8}}$. The same average fiber diameter was obtained for the three peptides: 2.8 $\pm 0.4 \mathrm{~nm}$ in good agreement with the formation of $\beta$-sheet fibers. Indeed the theoretical width of the octa-peptides in a fully extended $\beta$-sheet conformation is $\sim 2.8 \mathrm{~nm}$. AFM was used to visualize the fibers formed (Figure 2C). For F8 and FE, fibers with diameter of $\sim 3 \mathrm{~nm}$ were obtained in good agreement with SAXS. In the case of V8, thick fiber aggregates were observed; nevertheless, the thinnest fibers observed in this case too have a diameters of $\sim 3 \mathrm{~nm}$, again in good agreement with the SAXS findings. AFM images obtained can be affected by specific interactions of the peptides/peptide fibers with the negatively charged mica surface and/or drying effects and therefore should not be overinterpreted. ${ }^{43,48}$ Nevertheless, the difference in images obtained clearly underline the difference in physicochemical properties of these three peptides.

Indeed the critical gelation concentrations (CGC) and shear moduli $\left(G^{\prime}\right)$ of the corresponding hydrogels were found to differ significantly depending on the peptide used. V8 was found to form a viscous solution at $8.9 \mathrm{mM}$, while F8 and F9 formed self-supporting hydrogels. The $G^{\prime}$ of the hydrogels were measured at $26.8 \mathrm{mM}$, above the CGC of all three peptides. F8 hydrogel was found to have a significantly higher $G^{\prime}, 7900 \pm$ $1700 \mathrm{~Pa}$, compared to V8 and FE, $900 \pm 40 \mathrm{~Pa}$ and $800 \pm 80$ $\mathrm{Pa}$, respectively. The difference in gelation properties of these

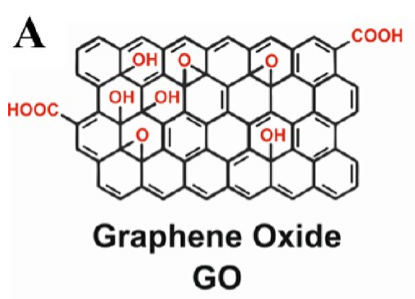

hydrophilic

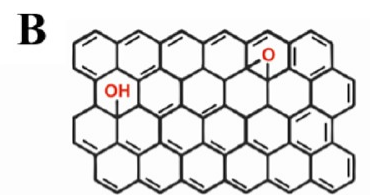

Reduced Graphene Oxide rGO

hydrophobic

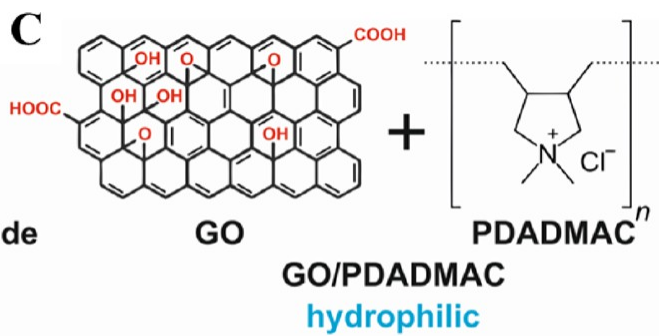

$\zeta=38.3 \pm 3.3 \mathrm{mV}(\mathrm{pH} \mathrm{3.5)}$;

$18.5 \pm 0.4 \mathrm{mV}(\mathrm{pH} \mathrm{6})$

D

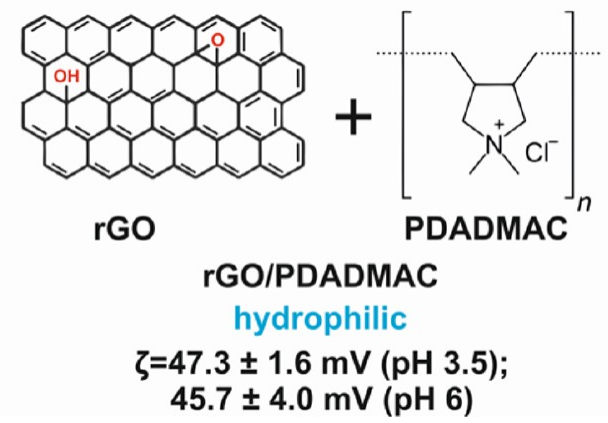

$\mathbf{E}$
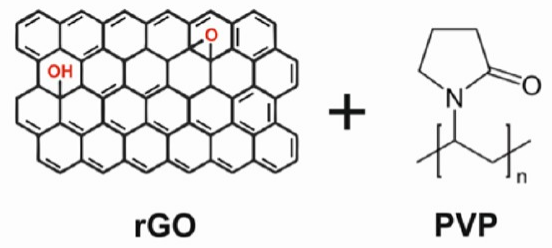

PVP

$$
\begin{gathered}
\text { rGO/PVP } \\
\text { hydrophilic } \\
\zeta=-0.6 \pm 0.4 \mathrm{mV}(\mathrm{pH} \mathrm{3.5)} ; \\
-21.4 \pm 1.1 \mathrm{mV}(\mathrm{pH} \mathrm{6})
\end{gathered}
$$

Figure 3. Schematic diagram of the graphene derivatives used and their surface chemistries. ( $\zeta$ : zeta-potential values of the GDs measured in solution at $0.01 \mathrm{mg} \mathrm{mL}^{-1}$ ). 
A
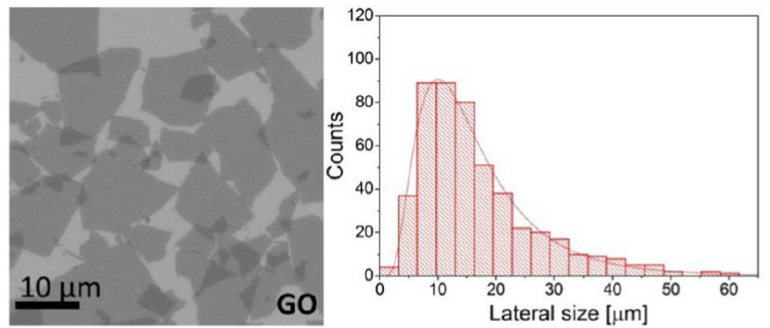

B
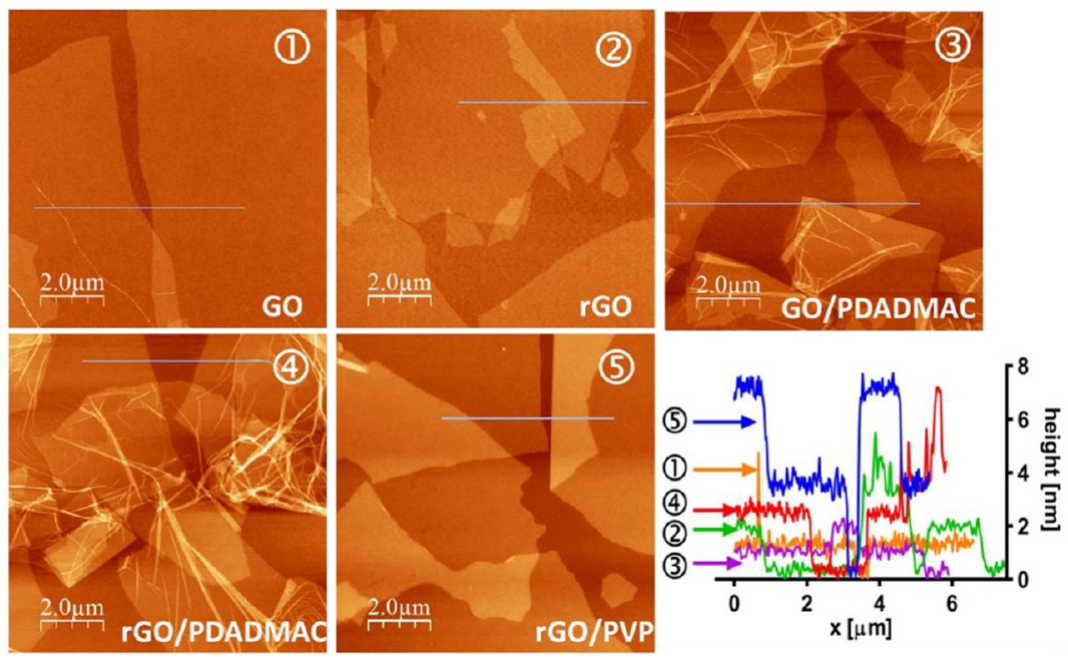

Figure 4. (A) SEM image of GO flakes master-batch and their lateral size distribution. (B) AFM images of the GDs and corresponding flake height measurements (line indicates height measurement scan location).

three peptides is thought to be linked to their different hydrophilicities (Figure 1B). Indeed as mentioned above, $\mathrm{V}$ is less hydrophobic than F. For FE, the difference in hydrophobicity is linked to the different $\mathrm{pH}$ at which the hydrogels are formulated. E becomes more hydrophilic around neutral $\mathrm{pH}^{49}$ resulting in the overall hydrophobicity of $\mathrm{FE}$ at $\mathrm{pH} 6$ being lower than $\mathrm{F} 8$ and $\mathrm{V} 8$ at $\mathrm{pH}$ 3.5. $\mathrm{Clog} P$ is a crude measure of the overall hydrophobicity of the peptides that does not take into consideration the location of the different residues in the overall fibrillar structure. As mentioned above, the $\mathrm{V}$ and $\mathrm{F}$ side groups are located in the core of the fibers (Figure 1C), therefore the increased hydrophobicity of $\mathrm{F}$, even in $\mathrm{FE}$, is thought to lead to the stabilization of the core of the fibers increasing their cohesion and their persistence length resulting in lower CGCs. ${ }^{42,50,51}$ The peptide fibers will carry the same charge, positive or negative, in all three systems and therefore there will be a long-range electrostatic repulsion between them. Hydrophobic and $\pi-\pi$ interactions, which are attractive and short-range, are thought to play a key role in stabilizing fiberfiber contacts, in other words, the network cross-links. In particular, as mentioned above, the first residue in these sequences can interact with the outer environment and therefore is thought to play a key role in the formation and stabilization of these cross-links. For F8 hydrogel, the combination of high overall hydrophobicity and the presence of $\mathrm{F}$ (side group able to $\pi-\pi$ bond) at the edge of the fibers is thought to lead to the formation of strong/stable cross-links, resulting in a high effective network cross-linking density and a high $G^{\prime}$. For FE hydrogel, the high hydrophilicity of this peptide at $\mathrm{pH} 6$ is thought to result in less stable cross-links and therefore in a lower effective network cross-linking density, resulting in a lower $G^{\prime}$. For V8 hydrogel, the combination of lower peptide overall hydrophobicity compared to F8 and the presence of $\mathrm{V}$ (side group unable to $\pi-\pi$ bond) instead of $\mathrm{F}$ is thought in this case also to lead to a lower effective crosslinking density and therefore a lower $G^{\prime}$. Ultimately, the final properties of these hydrogels are directly affected by the balance between two main forces: electrostatic repulsion, which keeps fibers apart leading to low mechanical properties, and hydrophobic and/or $\pi-\pi$ interactions, which are attractive and promote fiber-fiber contacts leading to high mechanical properties.

Five graphene derivatives with varying surface chemistries (Figure 3) were used to formulate hybrid hydrogels. The lateral size distribution of GO was a typically broad log-normal distribution with a mean size of $17 \pm 10 \mu \mathrm{m}$ (Figure 4A). It is estimated from XPS that $30 \%$ of the surface of GO was covered with hydrophilic oxygen-containing groups (Figure ESI 3$)^{32}$ $(-\mathrm{OH},-\mathrm{COOH},=\mathrm{O})$. GO was therefore water dispersible and had a highly negatively charged surface as confirmed by zeta-potential $(\zeta)$ measurements (Figure 3A).

Reduced GO (rGO) was synthesized by reduction of GO with ascorbic acid (AA) following the method described by Fernandez-Merino et al. ${ }^{33}$ The reduction was confirmed by XPS, and the rGO obtained was shown to have few hydrophilic oxygen containing groups (12\%) on its surface (Figure ESI 3). ${ }^{52}$ rGO is therefore highly hydrophobic and not dispersible in water ( $\zeta$ could not be measured). The thicknesses of the GO and rGO flakes were confirmed by AFM and were found to be consistent with single flake thicknesses: $1.1 \pm 0.3 \mathrm{~nm}$ (Figure 4B).

In order to invert the charge at the surface of the GDs, GO and rGO were coated with PDADMAC, a highly cationic polymer that strongly binds to the surface of these two GDs through electrostatic and hydrophobic interactions. The thickness measurements performed using AFM of the 

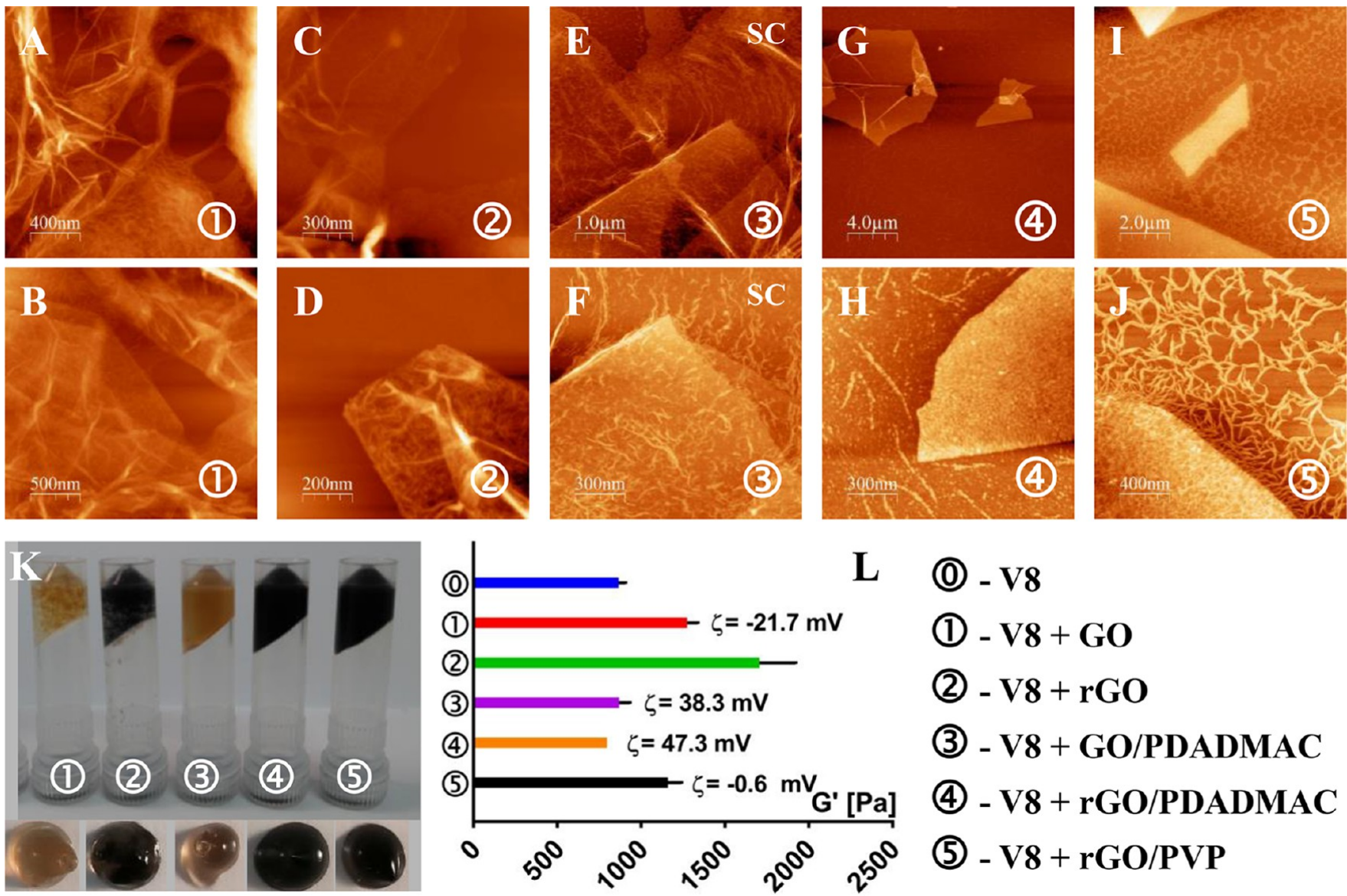

Figure 5. (A-J) AFM images obtained for the V8 + GDs dispersions prepared at $0.5 \mathrm{mM}$ peptide concentration and $0.5 \mathrm{mg} \mathrm{mL}^{-1} \mathrm{GDs}$ concentration. All samples were prepared by drop-casting unless otherwise stated (SC: spin coating). (K,L) Photographs and shear moduli of V8 + GDs hybrid hydrogels prepared at $26.8 \mathrm{mM}$ peptide concentration and $0.5 \mathrm{mg} \mathrm{mL}^{-1} \mathrm{GD}$ concentration ( $\zeta$ : corresponding solutions zeta-potential; see text for more details).

PDADMAC-coated GO and rGO flakes, $2.0 \pm 0.4$ and $2.5 \pm$ $0.4 \mathrm{~nm}$, respectively, confirm that the polymer fully covers the flakes (Figure 4B). Both of these GDs were therefore found to be water dispersible and to carry a high positive charge on their surface as confirmed by $\zeta$ measurements (Figure 3C,D).

Finally rGO was also coated with PVP, a nonionic polymer. As can be seen from AFM in this case too, full coverage of the flakes through hydrophobic interactions was achieved, resulting in an average flake thickness of $3.5 \pm 0.5 \mathrm{~nm}$ (Figure 4B). $\mathrm{rGO} / \mathrm{PVP}$ flakes were found to be water dispersible and to carry almost no charge at $\mathrm{pH} 3.5$ and a negative charge at $\mathrm{pH} 6$ (Figure $3 \mathrm{E}$ ) due to the increased electronegativity of the rGO flakes at higher $\mathrm{pH}$.

In order to investigate how peptide fibers interact with GDs flakes, AFM was used to image peptide/GDs dispersions. In order to facilitate imaging, the peptide concentration was reduced to $0.5 \mathrm{mM}$, significantly below the CGC of the three peptides, while the GD concentration was kept constant at 0.5 $\mathrm{mg} \mathrm{mL} \mathrm{m}^{-1}$. The only GD that could not be dispersed in a stable manner was rGO due to its high hydrophobicity. In order to prepare stable dispersions of $\mathrm{rGO}$, the reduction of $\mathrm{GO}$ was done in situ after dispersing it in the peptide solution. The same reduction methodology as described above was used. Hybrid hydrogels were also prepared using all five GDs at $26.8 \mathrm{mM}$, above the CGC of the three peptides, keeping the GD concentration at $0.5 \mathrm{mg} \mathrm{mL}^{-1}$. In this case too, peptide $+\mathrm{rGO}$ hybrid hydrogels were prepared by reducing GO in situ.
In Figure 5 the AFM images obtained for the V8 dispersions prepared with the different GDs as well as photographs of the corresponding hydrogels and their shear moduli are presented. As can be seen from Figure $5 \mathrm{~A}-\mathrm{C}$, GO and rGO flakes are fully covered by the peptide fibers with fibrillar "bridges" being observed between flakes in the case of GO. V8 fibers are positively charged at $\mathrm{pH} 3.5$, while GO flakes surfaces will carry negative charges resulting in strong electrostatic attractive interactions. rGO will also carry a low negative charge on its surface due to the presence of residual oxygen containing groups, but in this case, the dominating interaction between peptide fibers and flakes is thought to be hydrophobic, promoting in this case too strong interactions. For these two GDs, both electrostatic and hydrophobic interactions result in the peptide fibers adhering to the flakes. The corresponding hybrid hydrogels (Figure 5K) show that a significant level of macroscopic flake aggregation occurred during sample preparation. This is somehow expected for $\mathrm{rGO}$, which is insoluble. For GO, which is soluble, this is thought to be due to the peptide fibers covering the flakes masking the surface charges, leading to hydrophobic-driven aggregation of peptide fibers-covered flakes. The shear moduli of the hydrogels were observed to increase compared to pure V8 hydrogels (Figure $5 \mathrm{~L})$. The reinforcement of the hydrogels mechanical properties is thought to result from the additional stable network crosslinks generated by the presence of these two GDs through their strong interaction with the fibers. This reinforcement 

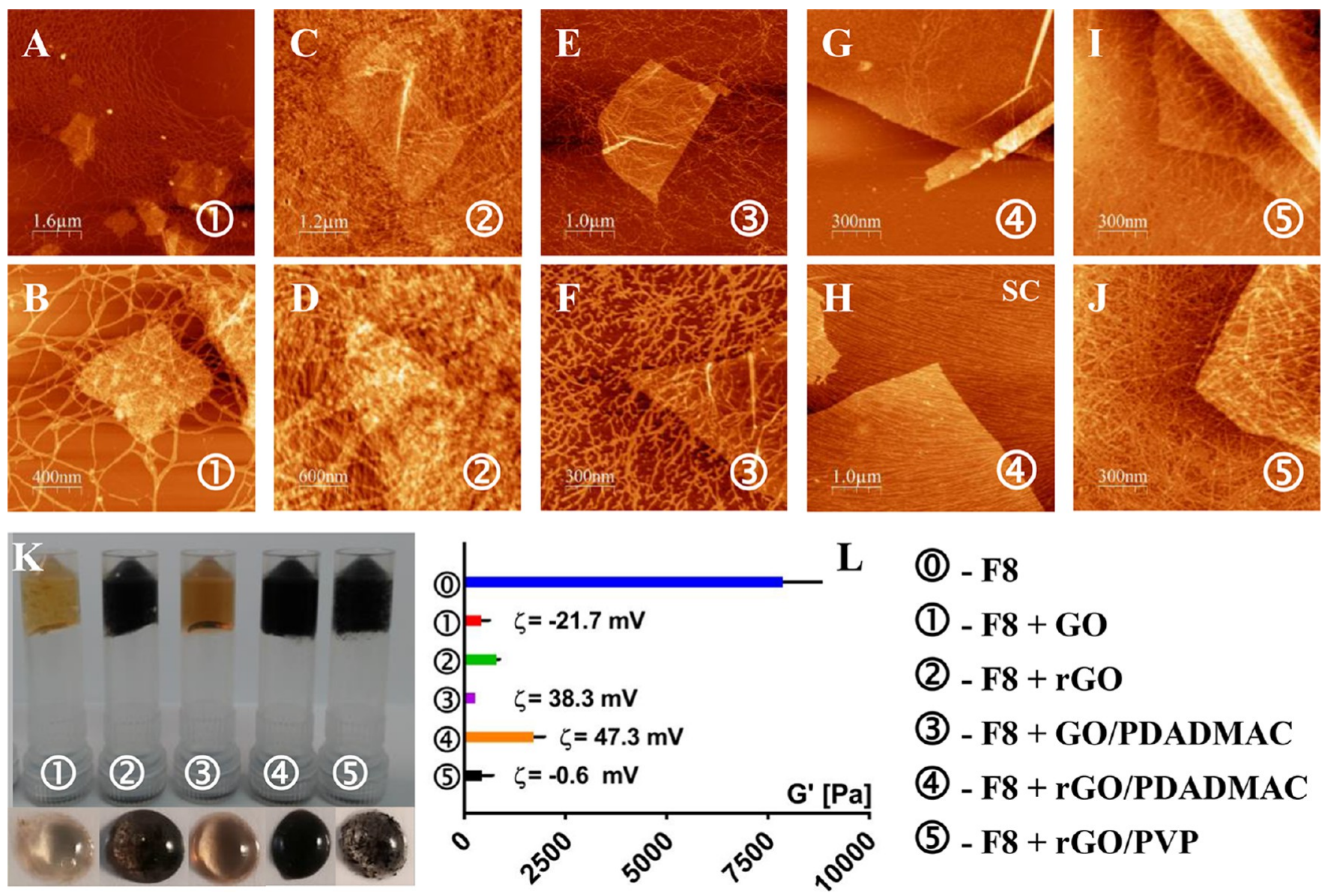

Figure 6. (A-J) AFM images obtained for the F8 + GDs dispersions prepared at $0.5 \mathrm{mM}$ peptide concentration and $0.5 \mathrm{mg} \mathrm{mL}^{-1} \mathrm{GDs}$ concentration. All samples were prepared by drop-casting unless otherwise stated (SC: spin coating). (K,L) Photographs and shear moduli of F8 + GDs hybrid hydrogels prepared at $26.8 \mathrm{mM}$ peptide concentration and $0.5 \mathrm{mg} \mathrm{mL}^{-1} \mathrm{GDs}$ concentration ( $\zeta$ : corresponding solutions zeta-potential; see text for more details).

mechanism is akin to reinforcement processes observed in nanocomposite materials, which relies on strong interaction between the matrix and the nanofillers to allow stress transfer.

When the GDs are covered with PDADMAC, which results in positively charged surfaces, no interactions between the peptide fibers and the GD flakes are observed. As can be seen from Figure $5 \mathrm{E}-\mathrm{H}$ peptide fibers were found to cover neither GO/PDADMAC nor rGO/PDADMAC flakes. In this case, electrostatic repulsion is not only preventing peptide fibers from adhering to the flakes, but the AFM images also suggest that the presence of the strongly cationic flakes affect the peptide ability to form fibers. As far as the hydrogels are concerned (significantly higher peptide concentration), no macroscopic aggregation of the flakes is observed, and the $G^{\prime}$ were found not to be affected by the addition of these two GDs (Figure 5L), suggesting that the fibrillar network formed by this peptide is flexible enough to accommodate the flakes spatially (no interactions) without its overall mechanical properties being affected. This is in good agreement with the peptide fibers and the flakes not interacting, resulting in the network and the filler being decoupled. For the PVP-covered rGO, strong interactions between the flakes and the peptide fibers are observed (Figure 5I,J). In this case, the GD flakes are not charged, and the interaction between the peptide fibers and the flakes are thought to be mainly hydrophobic. No significant macroscopic aggregation is observed for this GD, but, as for
GO and rGO, the hydrogel's $G^{\prime}$ increases when $\mathrm{rGO} / \mathrm{PVP}$ is added (Figure 5K,L).

F8 fibers will also carry a positive charge at $\mathrm{pH}$ 3.5. The main difference with V8 is its increased hydrophobicity and ability to interact via $\pi-\pi$ stacking due to the presence of F. AFM imaging of F8 is more challenging due to the high cohesion of the fibers and highly cross-linked network formed by this peptide (see above discussion) resulting in the formation of dense fibrillar structures even at low concentration. Nevertheless, similar results were obtained as for V8. For GO and rGO, strong interactions between the peptide fibers and the flakes can be observed with the peptide fibers, forming a dense cover on the surface of the flakes (Figure 6A-D). Differently from V8 system, when the GDs are covered with PDADMAC and their surface charge made positive, F8 fibers could still be deposited on the surface of the flakes. The fiber's "shape" seems not to be affected by the presence of the flakes suggesting simple deposition on the surface pointing toward weak interactions. These observations suggest that the peptideincreased hydrophobicity and fibers-increased cohesion (see above discussion) allow in this case the fibers to come in contact with the flakes despite the strong electrostatic repulsion. rGO/PVP fibers were also found to cover the surface of the flakes without the fiber "shapes" being significantly affected. As for F8, significant macroscopic aggregation of $\mathrm{GO}$ and $\mathrm{rGO}$ flakes was observed in the 

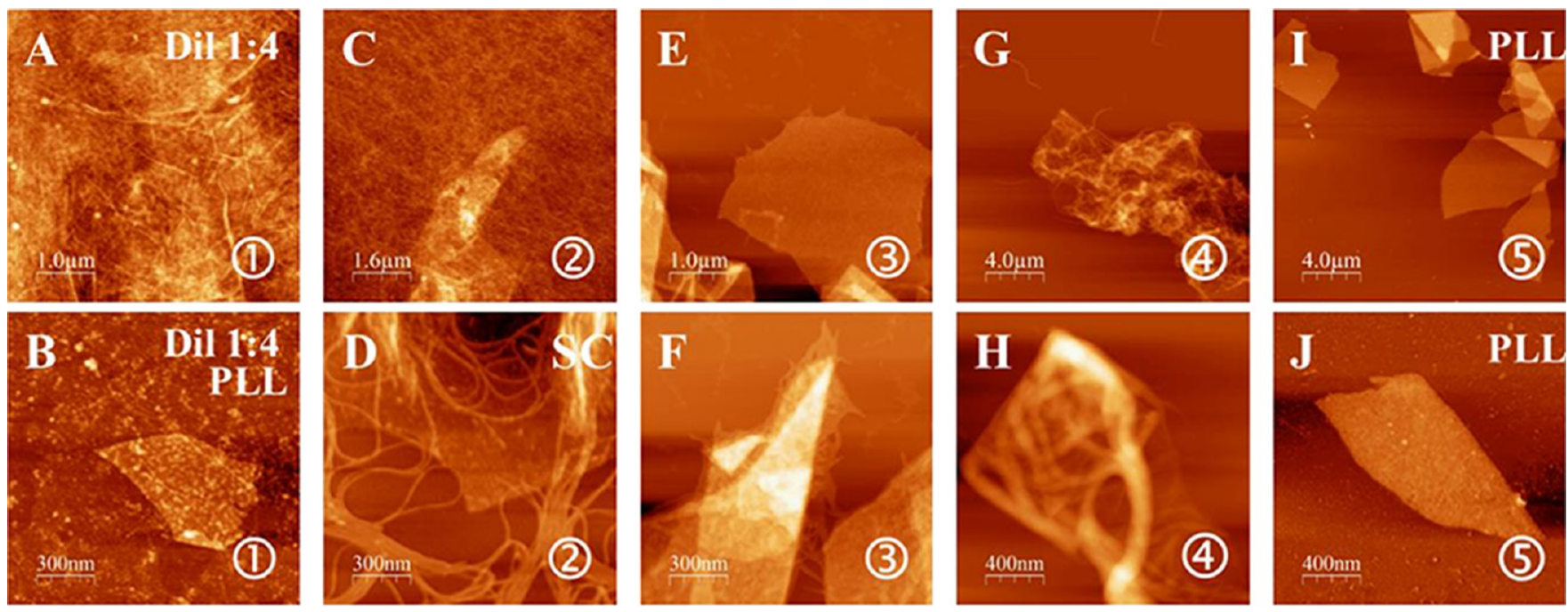
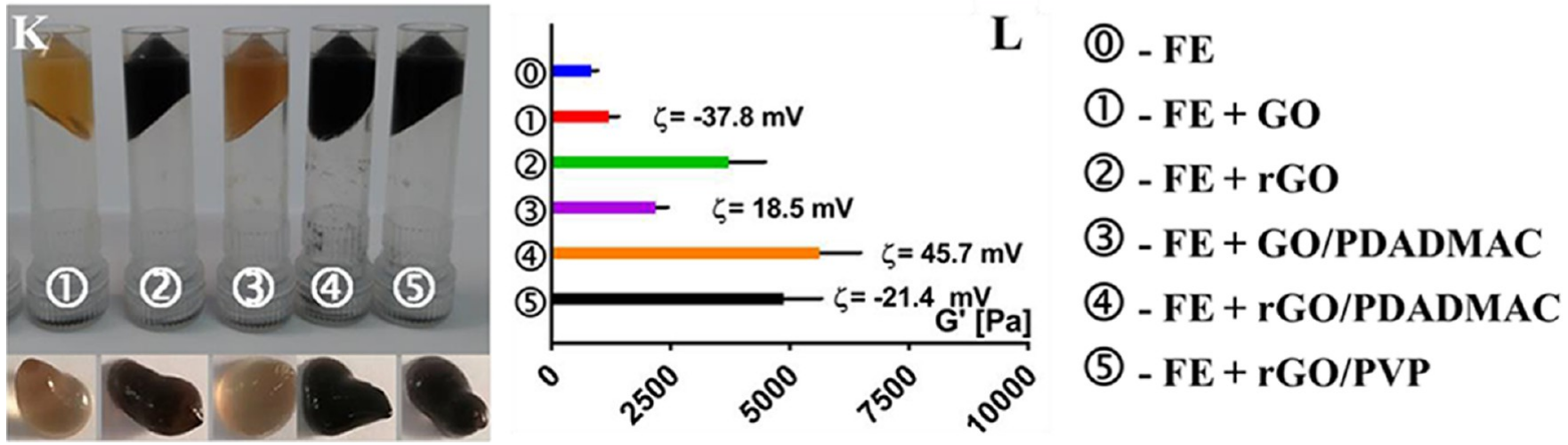

Figure 7. (A-J) AFM images obtained for the F8 + GDs dispersions prepared at $0.5 \mathrm{mM}$ peptide concentration and $0.5 \mathrm{mg} \mathrm{mL}^{-1} \mathrm{GDs}$ concentration. All samples were prepared by drop-casting unless otherwise stated (SC: spin coating). (K,L) Photographs and shear moduli of FE + GDs hybrid hydrogels prepared at $26.8 \mathrm{mM}$ peptide concentration and $0.5 \mathrm{mg} \mathrm{mL}^{-1}$ GDs concentration ( $\zeta$ : corresponding solutions zeta-potential; see text for more details).

corresponding hybrid hydrogels. In this case, macroscopic aggregation of flakes was also observed for rGO/PVP, probably due to the higher hydrophobicity of this peptide. For the PDADMAC-covered GO and rGO, no macroscopic aggregation was observed, suggesting that electrostatic repulsion between fibers and flakes prevents significant aggregation of these GDs during sample preparation. In the case of F8 though, the addition of any of the GDs results in a significant decrease in the hydrogels' $G^{\prime}$. Pure F8 hydrogel has a high $G^{\prime}$ compared to other sequences in this family of peptide including V8. As discussed above, this high observed $G^{\prime}$ is thought to originate from the strong cohesion and overall higher cross-linking efficiency of F8 fibers and network, respectively. One possible explanation for the results observed is the sequestration of the peptide fibers on the surface of the GDs. As shown via AFM (Figure 6A-J) for all the GDs, fibers were always able to come in contact with the flakes. For GO/PDADMAC and rGO/ PDADMAC, for which fibers and flakes carry positive charges, it is thought that once the fibers come in contact with the GDs, hydrophobic interactions become dominant, resulting in the fibers adhering to the GDs. Due to the large surface area of the GDs, the sequestration of the fibers would result in the actual concentration of fibers and cross-links contributing to the network elasticity decreasing, resulting in lower mechanical properties. This interpretation seems to be supported by the fact that the higher $G^{\prime}$ (still less than a third of pure F8) was obtained for $\mathrm{rGO} / \mathrm{PADADMAC}$, which is the GD carrying the highest positive charge and for which significant deposition of fibers on the flakes could be observed only after spin coating. Due to the higher cross-link density of the F8 system, this effect is detrimental to the overall mechanical properties of the hydrogels, while it seems not to be the case for V8. Our results suggest that the effect of adding GDs to these hydrogels is a balance between fiber sequestrations on the GDs surfaces and its detrimental effect on the overall network fiber and cross-link densities that will lead to lower $G^{\prime}$ (F8 case) and the additional strong physical network cross-linking resulting from fibers adhering on the surface of GDs, which will contribute to the overall reinforcement of the mechanical properties of the network, leading to higher $G^{\prime}$ (V8 case). This balance will be affected by the strength/stability of the fiber-fiber cross-links formed by each peptide system.

$\mathrm{FE}$ at $\mathrm{pH} 6$ will be negatively charged. In order to image GO dispersion, the mica surface had to be coated with PLL and made positive and the sample diluted. As can be seen from Figure $7 \mathrm{~A}$ and $\mathrm{B}$ in this case no interaction between peptide fibers and the flakes was observed. Similarly to V8 + GO/ PDADMAC and V8 + rGO/PDADMAC, the strong electrostatic repulsion seems to affect the ability of the peptide to selfassemble and form fiber in the vicinity of the flakes. In this case also, no macroscopic aggregation of the flakes is observed in the bulk hydrogel, and the $G^{\prime}$ was not affected by the introduction 
of this GD (Figure 7K,L). As mentioned above, although rGO will carry a small negative charge on its surface, the dominant interaction between the peptide fibers and the flakes is hydrophobic. In this case, the fibers can be seen to cover and interact with the flakes. When GO and rGO are covered with PDADMAC, and their surfaces are made positive, strong interactions between the peptide fibers and the flakes as expected occur with the flakes being fully covered by fibers. In all three cases, when the fibers are found to adhere to the flakes, the $G^{\prime}$ of the bulk hydrogel increases. Interestingly, the $G^{\prime}$ of $\mathrm{FE}+$ rGO hydrogel, where interactions between peptide fibers and flakes are dominated by hydrophobic interactions, was found to be higher that the $G^{\prime}$ of $\mathrm{FE}+\mathrm{GO} / \mathrm{PDADMAC}$ hydrogel (GD carrying the lowest positive charge) but lower than the $G^{\prime}$ of $\mathrm{FE}+\mathrm{rGO} / \mathrm{PDADMAC}$ hydrogels (GD carrying the highest positive charge) giving a sense of the relative strength of these two type of interactions.

Finally, for the PVP-covered rGO flakes, no fibers-covered flakes could be observed (Figure 7I,J), which is expected, as this GD carries a negative charge (Figure 3). Surprisingly though, the hydrogel's $G^{\prime}$ was found to increase when this GD is added, suggesting that hydrophobic interactions in this case are able to overcome electrostatic repulsion, and some level of fiber adhesion to flakes occurs in the hydrogel. It should be kept in mind that hydrogels are formed at significantly higher peptide concentration compared to the dispersions imaged via AFM. Although the nature of the interactions between the fibers and the flakes will not change, as the $\mathrm{pH}$ conditions between the two sets of sample were kept identical, the fiber density in the hydrogels will be significantly higher. As a result, the probability of fibers coming in close contact with the flakes is high, and, as mentioned above, at short-range, hydrophobic interaction will be dominant, resulting in the fibers adhering to the flakes.

At the difference in the V8 and F8 systems, where macroscopic flake aggregation is observed, when strong attractive electrostatic interactions exist between fibers and flakes, no macroscopic aggregation of the flakes is observed for the $\mathrm{FE}+\mathrm{GO} / \mathrm{PDADMAC}$ and $\mathrm{FE}+\mathrm{rGO} / \mathrm{PDADMAC}$ hydrogels. As for the other two systems, when the positive charged fibers cover the flakes, charge screening will occur, but in this case the hydrophilicity of FE and therefore the fibers is thought to favor the solubilization of the fibers-covered flakes and prevent their aggregation during sample preparation.

As FE hydrogels were prepared around physiological $\mathrm{pH}$, they were used to confirm the biocompatibility of the hybrid hydrogels with GO and rGO by encapsulating hMSC and culturing them in 3D over 14 days. In Figure 8 live-dead staining images obtained at days 1,7 , and 14 are presented for $\mathrm{FE}, \mathrm{FE}+\mathrm{GO}$, and $\mathrm{FE}+\mathrm{rGO}$ hydrogels. The images show high cell viability $(>95 \%)$ for all three hydrogels at all time points, confirming the low cytotoxicity of these materials. In the case of $\mathrm{FE}+\mathrm{rGO}$, the results also suggest that the in situ reduction process does not influence the cytotoxicity of the hydrogel. For FE hydrogels, as can be seen at 14 days, clustering of cells can be observed. This is typical of hydrogels where there is a lack of adhesion of the cells to the fibrillar network. It should be kept in mind that these preliminary experiments were performed on nonfunctionalized hydrogels and therefore no adhesion is indeed expected of the cells on the fibers. When GO (no change in $G^{\prime}$ ) and rGO (higher $G^{\prime}$ ) are introduced, a similar effect is observed but from the early time point of day 7 , the cell clustering being more marked at day 14 compared to FE. The in-depth study of the effect of introducing GDs into this family
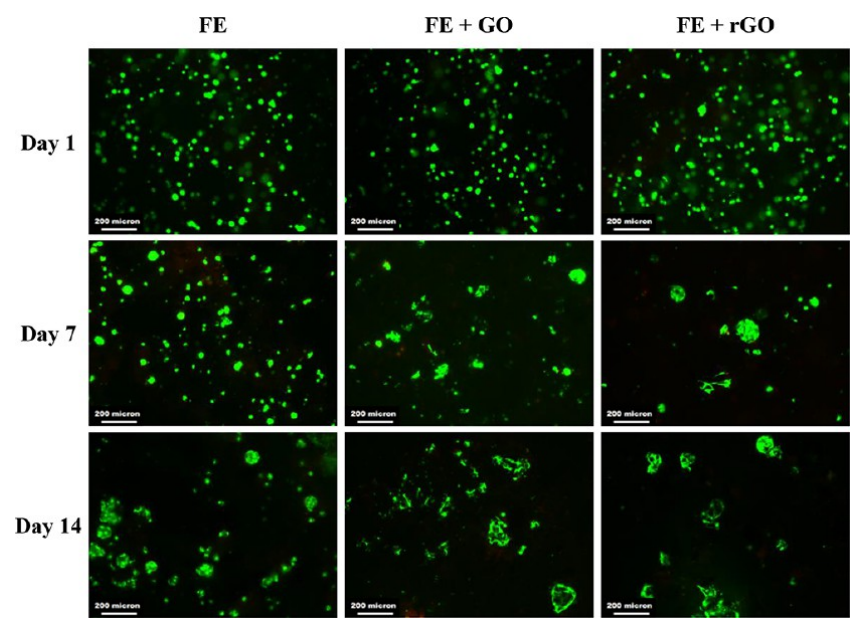

Figure 8. Fluorescence microscopy live (green)/dead (red) staining images of hMSCs cells cultured in $3 \mathrm{D}$ in the three hydrogels FE, FE + GO, and FE + rGO. Scale bar: $200 \mu \mathrm{m}$.

of hydrogels on cell behavior is beyond the scope of this Article, but these preliminary results clearly show that introducing GDs will affect cell behavior.

\section{CONCLUSIONS}

By varying the physicochemical properties of the peptides and the surface chemistry of the GDs, we have shown how the interplay between two main types of interactions, electrostatic and hydrophobic, affects the interactions between peptide fibers and GD flakes and how these, in turn, affect the hydrogels' mechanical properties. Long-range electrostatic interactions between fibers and flakes can be attractive or repulsive depending on the charge carried by the peptides and the GDs. On the other hand, short-range hydrophobic (and $\pi-\pi$ in the case of $\mathrm{F}$ containing peptides) interactions are always attractive, and their strength depends on the respective hydrophobicities of the peptides and the GDs. When both interactions are attractive (peptides and GDs carry opposite charges) peptide fibers were found to strongly interact with the flakes. For V8 and FE, this led to an increase in the hydrogels $G^{\prime}$, which is thought to result from the additional stable network cross-links resulting from the fibers adhering to the flakes. When electrostatic and hydrophobic interactions are in competition, their relative strength affects the final properties of the hydrogel. When electrostatic repulsion is dominant, as in the case of $\mathrm{V} 8+\mathrm{GO} / \mathrm{PDADMAC}, \mathrm{V} 8+\mathrm{rGO} / \mathrm{PDADMAC}$, and $\mathrm{FE}+\mathrm{GO}$, fibers do not interact with the flakes, and the hydrogels' mechanical properties are not affected by the presence of the GDs. For $\mathrm{FE}+\mathrm{rGO}$ and $\mathrm{FE}+\mathrm{rGO} / \mathrm{PVP}$, where hydrophobic interactions are dominant (weak electrostatic repulsion), the fibers were found to interact and adhere to the flakes, resulting, as above, in an increase in the corresponding hydrogels' $G^{\prime}$.

For F8, the most hydrophobic peptide, a hydrogel with a significantly higher $G^{\prime}$ was obtained compared to V8 and FE hydrogels. This is thought to be due to the formation by this peptide of rigid fibers and stable fiber-fiber cross-links. For all the GDs, AFM imaging showed that the hydrophobic interactions between F8 fibers and GD flakes were strong enough to allow the fibers to adhere to some extent to the flakes. For this system it is thought that, due to the higher cross-link efficiency (stability and density), the sequestration of 
the peptide fiber on the surface of the GD flakes has a stronger detrimental effect, compared to V8 and FE. As a result, the introduction of any of the GDs resulted in hybrid hydrogels with significantly lower $G^{\prime}$.

Finally, by culturing hMSC in 3D, we have also shown that, for FE hydrogels, the addition of GO and rGO does not affect the overall cytotoxicity of these hydrogels, making then suitable for cell culture and tissue engineering applications.

This work clearly shows how interactions between peptides and GDs can be used to tailor the mechanical properties of the resulting hydrogels, allowing the incorporations of these nanofillers in a controlled way, and opening the possibility to exploit their intrinsic properties to design novel hybrid peptide hydrogels for biomedical applications.

\section{ASSOCIATED CONTENT}

\section{S Supporting Information}

The Supporting Information is available free of charge on the ACS Publications website at DOI: 10.1021/acs.biomac.8b00333.

Graphs showing the theoretical charge carried by the three peptides vs $\mathrm{pH}$ (Figure ESI 1), SAXS scattering pattern $(\log I(q)$ vs $\log q)$ obtained for V8, F8, and FE (Figure ESI 2), and wide X-ray photoelectron spectroscopy (XPS) scan of GO and $\mathrm{rGO}$, respectively, and corresponding $\mathrm{C} 1$ regions curves (PDF)

\section{AUTHOR INFORMATION}

\section{Corresponding Author}

*Phone: +44 161306 5981; Fax: +44 161306 3586; e-mail: a. saiani@manchester.ac.uk.

\section{ORCID}

Jacek K. Wychowaniec: 0000-0002-6597-5242

Aravind Vijayaraghavan: 0000-0001-8289-2337

Alberto Saiani: 0000-0002-5504-8306

\section{Present Addresses}

Current address: NanoBioMedical Centre, Adam Mickiewicz University, ul. Umultowska 85, 61-614 Poznań, Poland; e-mail: jacek.wychowaniec@amu.edu.pl.

\$Current address: School of Pharmacy and Biomedical Sciences, University of Central Lancashire, Preston PR1 2HE, U.K.

\section{Author Contributions}

The manuscript was written through contributions of all authors. All authors have given approval to the final version of the manuscript.

\section{Notes}

The authors declare no competing financial interest.

\section{ACKNOWLEDGMENTS}

The authors acknowledge financial support from the Engineering and Physical Sciences Research Council (EPSRC): Early Career Fellowship (EP/K016210/1), Northwest Nanoscience Doctoral Training Centre (NOWNANO DTC) (EP/ G03737X/1) and EPSRC doctoral training award (DTA) from the School of Materials, University of Manchester. The authors are also grateful to Diamond Light Source for awarding beam time (SM12950 and SM15246) to this project and to the staff on beamline I22 for their support with the SAXS experiments.

\section{REFERENCES}

(1) Mata, A.; Azevedo, H. S.; Botto, L.; Gavara, N.; Su, L. New Bioengineering Breakthroughs and Enabling Tools in Regenerative Medicine. Curr. Stem Cell Rep. 2017, 3 (2), 83-97.

(2) Patterson, J.; Martino, M. M.; Hubbell, J. A. Biomimetic materials in tissue engineering. Mater. Today 2010, 13 (1-2), 14-22.

(3) Chin, S. Y.; Poh, Y. C.; Kohler, A.-C.; Compton, J. T.; Hsu, L. L.; Lau, K. M.; Kim, S.; Lee, B. W.; Lee, F. Y.; Sia, S. K. Additive manufacturing of hydrogel-based materials for next-generation implantable medical devices. Sci. Robotics 2017, 2 (2), eaah6451.

(4) Aguilar, J. P.; Lipka, M.; Primo, G. A.; Licon-Bernal, E. E.; Fernández-Pradas, J. M.; Yaroshchuk, A.; Albericio, F.; Mata, A. 3D Electrophoresis-Assisted Lithography (3DEAL): 3D Molecular Printing to Create Functional Patterns and Anisotropic Hydrogels. Adv. Funct. Mater. 2018, 28, 1703014.

(5) Zhang, S. G. Emerging biological materials through molecular self-assembly. Biotechnol. Adv. 2002, 20 (5-6), 321-339.

(6) Castillo Diaz, L. A.; Saiani, A.; Gough, J. E.; Miller, A. F. Human osteoblasts within soft peptide hydrogels promote mineralisation in vitro. J. Tissue Eng. 2014, 5, 2041731414539344.

(7) Sinthuvanich, C.; Haines-Butterick, L. A.; Nagy, K. J.; Schneider, J. P. Iterative design of peptide-based hydrogels and the effect of network electrostatics on primary chondrocyte behavior. Biomaterials 2012, 33 (30), 7478-7488.

(8) Haines-Butterick, L.; Rajagopal, K.; Branco, M.; Salick, D.; Rughani, R.; Pilarz, M.; Lamm, M. S.; Pochan, D. J.; Schneider, J. P. Controlling hydrogelation kinetics by peptide design for threedimensional encapsulation and injectable delivery of cells. Proc. Natl. Acad. Sci. U. S. A. 2007, 104 (19), 7791-7796.

(9) Kumar, D.; Workman, V. L.; O’Brien, M.; McLaren, J.; White, L.; Ragunath, K.; Rose, F.; Saiani, A.; Gough, J. E. Peptide Hydrogels-A Tissue Engineering Strategy for the Prevention of Oesophageal Strictures. Adv. Funct. Mater. 2017, 27 (38), 1702424.

(10) Schneider, A.; Garlick, J. A.; Egles, C. Self-Assembling Peptide Nanofiber Scaffolds Accelerate Wound Healing. PLoS One 2008, 3 (1), e1410.

(11) Mujeeb, A.; Miller, A. F.; Saiani, A.; Gough, J. E. Self-assembled octapeptide scaffolds for in vitro chondrocyte culture. Acta Biomater. 2013, 9 (1), 4609-4617.

(12) Wan, S.; Borland, S.; Richardson, S. M.; Merry, C. L. R.; Saiani, A.; Gough, J. E. Self-assembling peptide hydrogel for intervertebral disc tissue engineering. Acta Biomater. 2016, 46, 29-40.

(13) Morris, O.; Elsawy, M. A.; Fairclough, M.; Williams, K. J.; McMahon, A.; Grigg, J.; Forster, D.; Miller, A. F.; Saiani, A.; Prenant, C. In vivo characterisation of a therapeutically relevant self-assembling F-18-labelled -sheet forming peptide and its hydrogel using positron emission tomography. J. Labelled Compd. Radiopharm. 2017, 60 (10), 481-488.

(14) Rodriguez, A. L.; Wang, T. Y.; Bruggeman, K. F.; Horgan, C. C.; Li, R.; Williams, R. J.; Parish, C. L.; Nisbet, D. R. In vivo assessment of grafted cortical neural progenitor cells and host response to functionalized self-assembling peptide hydrogels and the implications for tissue repair. J. Mater. Chem. B 2014, 2 (44), 7771-7778.

(15) Mazza, M.; Patel, A.; Pons, R.; Bussy, C.; Kostarelos, K. Peptide nanofibres as molecular transporters: from self-assembly to in vivo degradation. Faraday Discuss. 2013, 166, 181-194.

(16) Saini, A.; Serrano, K.; Koss, K.; Unsworth, L. D. Evaluation of the hemocompatibility and rapid hemostasis of (RADA) 4 peptidebased hydrogels. Acta Biomater. 2016, 31, 71-9.

(17) Das, D.; Kar, T.; Das, P. K. Gel-nanocomposites: materials with promising applications. Soft Matter 2012, 8 (8), 2348-2365.

(18) Lu, H.; Zhang, S.; Guo, L.; Li, W. Applications of graphenebased composite hydrogels: a review. RSC Adv. 2017, 7 (80), 5100851020.

(19) Pan, C.; Liu, L.; Gai, G. Recent Progress of GrapheneContaining Polymer Hydrogels: Preparations, Properties, and Applications. Macromol. Mater. Eng. 2017, 302 (10), 1700184. 
(20) Song, H. S.; Kwon, O. S.; Kim, J.-H.; Conde, J.; Artzi, N. 3D hydrogel scaffold doped with $2 \mathrm{D}$ graphene materials for biosensors and bioelectronics. Biosens. Bioelectron. 2017, 89, 187-200.

(21) Goenka, S.; Sant, V.; Sant, S. Graphene-based nanomaterials for drug delivery and tissue engineering. J. Controlled Release 2014, 173, $75-88$.

(22) Ferrari, A. C.; Bonaccorso, F.; Fal'ko, V.; Novoselov, K. S.; Roche, S.; Boggild, P.; Borini, S.; Koppens, F. H. L.; Palermo, V.; Pugno, N.; Garrido, J. A.; Sordan, R.; Bianco, A.; Ballerini, L.; Prato, M.; Lidorikis, E.; Kivioja, J.; Marinelli, C.; Ryhanen, T.; Morpurgo, A.; Coleman, J. N.; Nicolosi, V.; Colombo, L.; Fert, A.; Garcia-Hernandez, M.; Bachtold, A.; Schneider, G. F.; Guinea, F.; Dekker, C.; Barbone, M.; Sun, Z. P.; Galiotis, C.; Grigorenko, A. N.; Konstantatos, G.; Kis, A.; Katsnelson, M.; Vandersypen, L.; Loiseau, A.; Morandi, V.; Neumaier, D.; Treossi, E.; Pellegrini, V.; Polini, M.; Tredicucci, A.; Williams, G. M.; Hong, B. H.; Ahn, J. H.; Kim, J. M.; Zirath, H.; van Wees, B. J.; van der Zant, H.; Occhipinti, L.; Di Matteo, A.; Kinloch, I. A.; Seyller, T.; Quesnel, E.; Feng, X. L.; Teo, K.; Rupesinghe, N.; Hakonen, P.; Neil, S. R. T.; Tannock, Q.; Lofwander, T.; Kinaret, J. Science and technology roadmap for graphene, related two-dimensional crystals, and hybrid systems. Nanoscale 2015, 7 (11), 45984810

(23) Krishna, K. V.; Menard-Moyon, C.; Verma, S.; Bianco, A. Graphene-based nanomaterials for nanobiotechnology and biomedical applications. Nanomedicine 2013, 8 (10), 1669-1688.

(24) Jakus, A. E.; Secor, E. B.; Rutz, A. L.; Jordan, S. W.; Hersam, M. C.; Shah, R. N. Three-Dimensional Printing of High-Content Graphene Scaffolds for Electronic and Biomedical Applications. ACS Nano 2015, 9 (4), 4636-4648.

(25) Yoon, H. H.; Bhang, S. H.; Kim, T.; Yu, T.; Hyeon, T.; Kim, B. S. Dual Roles of Graphene Oxide in Chondrogenic Differentiation of Adult Stem Cells: Cell-Adhesion Substrate and Growth FactorDelivery Carrier. Adv. Funct. Mater. 2014, 24 (41), 6455-6464.

(26) Nayak, T. R.; Andersen, H.; Makam, V. S.; Khaw, C.; Bae, S.; Xu, X.; Ee, P.-L. R.; Ahn, J.-H.; Hong, B. H.; Pastorin, G.; Oezyilmaz, B. Graphene for Controlled and Accelerated Osteogenic Differentiation of Human Mesenchymal Stem Cells. ACS Nano 2011, 5 (6), $4670-4678$

(27) La, W. G.; Jin, M.; Park, S.; Yoon, H. H.; Jeong, G. J.; Bhang, S. H.; Park, H.; Char, K.; Kim, B. S. Delivery of bone morphogenetic protein-2 and substance $\mathrm{P}$ using graphene oxide for bone regeneration. Int. J. Nanomed. 2014, 9, 107-116.

(28) Puvirajesinghe, T. M.; Zhi, Z. L.; Craster, R. V.; Guenneau, S. Tailoring drug release rates in hydrogel-based therapeutic delivery applications using graphene oxide. J. R. Soc., Interface 2018, 15 (139), 20170949.

(29) Sheikholeslam, M.; Pritzker, M.; Chen, P. Hybrid peptidecarbon nanotube dispersions and hydrogels. Carbon 2014, 71, 284293.

(30) Sheikholeslam, M.; Wheeler, S. D.; Duke, K. G.; Marsden, M.; Pritzker, M.; Chen, P. Peptide and peptide-carbon nanotube hydrogels as scaffolds for tissue \& 3D tumor engineering. Acta Biomater. 2018, 69, 107-119.

(31) Wu, J.; Chen, A.; Qin, M.; Huang, R.; Zhang, G.; Xue, B.; Wei, J.; Li, Y.; Cao, Y.; Wang, W. Hierarchical construction of a mechanically stable peptide-graphene oxide hybrid hydrogel for drug delivery and pulsatile triggered release in vivo. Nanoscale 2015, 7 (5), $1655-1660$.

(32) Rourke, J. P.; Pandey, P. A.; Moore, J. J.; Bates, M.; Kinloch, I. A.; Young, R. J.; Wilson, N. R. The Real Graphene Oxide Revealed: Stripping the Oxidative Debris from the Graphene-like Sheets. Angew. Chem., Int. Ed. 2011, 50 (14), 3173-3177.

(33) Fernandez-Merino, M. J.; Guardia, L.; Paredes, J. I.; Villar-Rodil, S.; Solis-Fernandez, P.; Martinez-Alonso, A.; Tascon, J. M. D. Vitamin C Is an Ideal Substitute for Hydrazine in the Reduction of Graphene Oxide Suspensions. J. Phys. Chem. C 2010, 114 (14), 6426-6432.

(34) Li, D.; Muller, M. B.; Gilje, S.; Kaner, R. B.; Wallace, G. G. Processable aqueous dispersions of graphene nanosheets. Nat. Nanotechnol. 2008, 3 (2), 101-105.
(35) Horcas, I.; Fernandez, R.; Gomez-Rodriguez, J. M.; Colchero, J.; Gomez-Herrero, J.; Baro, A. M. WSXM: A software for scanning probe microscopy and a tool for nanotechnology. Rev. Sci. Instrum. 2007, 78 (1), 013705

(36) Guenet, J.-M. Thermoreversible Gelation of Polymers and Biopolymers; Academic Press: London, 1992.

(37) Higgins, J. S.; Benoit, H. C. Polymer and Neutron Scattering; Clarendon Press: Oxford, 1994

(38) Guinier, A.; Fournet, G. Small-Angle Scattering of X-rays; John Wiley \& Sons, Inc.: New-York, 1955.

(39) Roe, R.-J. Methods of X-Ray and Neutron Scattering in Polymer Science; Oxford University Press: New York, 2000.

(40) Guilbaud, J.-B.; Saiani, A. Using small angle scattering (SAS) to structurally characterise peptide and protein self-assembled materials. Chem. Soc. Rev. 2011, 40 (3), 1200-1210.

(41) Elsawy, M. A.; Smith, A. M.; Hodson, N.; Squires, A.; Miller, A. F.; Saiani, A. Modification of beta-Sheet Forming Peptide Hydrophobic Face: Effect on Self-Assembly and Gelation. Langmuir 2016, 32 (19), 4917-4923.

(42) Gao, J.; Tang, C.; Smith, A. M.; Miller, A. F.; Saiani, A. Controlling self-assembling peptide hydrogel properties through network topology. Biomacromolecules 2017, 18 (3), 826-834.

(43) Saiani, A.; Mohammed, A.; Frielinghaus, H.; Collins, R.; Hodson, N.; Kielty, C. M.; Sherratt, M. J.; Miller, A. F. Self-assembly and gelation properties of alpha-helix versus beta-sheet forming peptides. Soft Matter 2009, 5 (1), 193-202.

(44) vandenAkker, C. C.; Engel, M. F. M.; Velikov, K. P.; Bonn, M.; Koenderink, G. H. Morphology and Persistence Length of Amyloid Fibrils Are Correlated to Peptide Molecular Structure. J. Am. Chem. Soc. 2011, 133 (45), 18030-18033.

(45) Aggeli, A.; Bell, M.; Carrick, L. M.; Fishwick, C. W. G.; Harding, R.; Mawer, P. J.; Radford, S. E.; Strong, A. E.; Boden, N. pH as a trigger of peptide beta-sheet self-assembly and reversible switching between nematic and isotropic phases. J. Am. Chem. Soc. 2003, 125 (32), 9619-9628

(46) Fishwick, C. W. G.; Beevers, A. J.; Carrick, L. M.; Whitehouse, C. D.; Aggeli, A.; Boden, N. Structures of helical beta-tapes and twisted ribbons: The role of side-chain interactions on twist and bend behavior. Nano Lett. 2003, 3 (11), 1475-1479.

(47) Bowerman, C. J.; Liyanage, W.; Federation, A. J.; Nilsson, B. L. Tuning beta-Sheet Peptide Self-Assembly and Hydrogelation Behavior by Modification of Sequence Hydrophobicity and Aromaticity. Biomacromolecules 2011, 12 (7), 2735-2745.

(48) Maity, S.; Zanuy, D.; Razvag, Y.; Das, P.; Aleman, C.; Reches, $M$. Elucidating the mechanism of interaction between peptides and inorganic surfaces. Phys. Chem. Chem. Phys. 2015, 17 (23), 1530515315 .

(49) Monera, O. D.; Sereda, T. J.; Zhou, N. E.; Kay, C. M.; Hodges, R. S. Relationship of Sidechain Hydrophobicity and alpha-Helical Propensity on the Stability of the Single-stranded Amphipathic alphaHelix. J. Pept. Sci. 1995, 1 (5), 319-329.

(50) Roberts, D.; Rochas, C.; Saiani, A.; Miller, A. F. Effect of Peptide and Guest Charge on the Structural, Mechanical and Release Properties of beta-Sheet Forming Peptides. Langmuir 2012, 28 (46), 16196-16206.

(51) Mohammed, A.; Miller, A. F.; Saiani, A. 3D networks from selfassembling ionic-complementary octa-peptides. Macromol. Symp. 2007, 251, 88-95.

(52) Erickson, K.; Erni, R.; Lee, Z.; Alem, N.; Gannett, W.; Zettl, A. Determination of the Local Chemical Structure of Graphene Oxide and Reduced Graphene Oxide. Adv. Mater. 2010, 22 (40), 4467-4472. 